\title{
Characterisation of current defects in deck parkings
}

Received (in revised form): 23rd May, 2005

\section{Jorge de Brito}

graduated in civil engineering and received his masters and doctorate degrees at IST-Technical University of Lisbon, Portugal, where he is an associate professor. He is a member of IABSE, FIB, CIB and IABMAS, as well as several reputed national engineering societies. His research work deals with deterioration, rehabilitation and management of concrete structures. He has recently co-authored the Handbook of Concrete Bridge Management (2004), published by ASCE Press.

\section{Fernando A. Branco}

is an American Concrete Institute (ACI) member and full professor of civil engineering at IST. He is Vice-Chairman of the IABSE Commission on 'Maintenance of Structures' and Consulting Member of ACl Committee No. 343 on the 'Evaluation of Concrete Bridges'. His primary research interests deal with the behaviour of bridges and other public works. He has recently co-authored the Handbook of Concrete Bridge Management (2004).

\section{José Roberto dos Santos}

is a PhD student at IST, where he received his masters degree in structural engineering. His research work deals with the evaluation of concrete structures, in situ testing and recycling of construction materials.

\section{Pedro Vaz Paulo}

is a PhD student at IST, where he received his masters degree in construction. His research work deals with information technology and building management systems.

\begin{abstract}
The effectiveness of prefabricated systems frequently used in the structure of deck parkings depends very much on an appropriate design of the ties and joints, in order to ensure a good seismic behaviour. In terms of durability, these structures are subject to both atmospheric carbon dioxide and vehicles' exhaust fumes, thus accelerating the carbonation process. The main pathologies from a set of deck parkings that were inspected are presented, as well as the conclusions arising from these inspections. The most frequent structural problems found were cracking in concrete columns, beams, corbels, slabs and brick masonry walls, non-tight expansion joints and various types of water infiltration. The main durability-connected problems detected concerned deposition of oxides and salts, reinforcement corrosion and deterioration near faulty pipes. Non-structural problems included faulty drainage systems, lighting deficiencies, railing deterioration and pavement cracking. In terms of carbonation progress, the use of even common paint in the architectural concrete elements was proven to be beneficial in some circumstances. The design of deck parkings needs to be durability-oriented due to the very aggressive conditions to which they are subjected.
\end{abstract} Arquitectura, Av. Rovisco Pais 1049-001 Lisboa, Portugal

Tel: +351218419709 Fax: +351218497650 E-mail: jb@civil.ist.utl.pt 


\section{Keywords:}

concrete deck parkings, carbonation, pathology, drainage problems, design rules

\section{INTRODUCTION}

Deck parkings have specific characteristics that must be considered in their design. In some countries, this requirement has even led to the development of specific recommendations for these structures. Indeed, deck parkings, being totally exposed to open air, present characteristics closer to the behaviour of bridges than, as currently categorised, buildings.

In terms of resistance, these structures must bear the live loads of the upper floor and, in some cases, important point loads. Concerning durability, the floors are subject to wear caused by vehicles and the action of aggressive elements such as atmospheric carbon dioxide and the exhaust fumes from car traffic. These structures are frequently designed on the basis of prefabricated elements. In such cases, and in particular when the deck parkings are built in strongly seismic areas (such as zone A in Portugal, which includes Lisbon), a good design of the ties and joints is paramount as a guarantee of the good performance of the structure under seismic action.

This paper presents the main pathologies found in a set of 13 Portuguese deck parkings inspected over a one-year period. The work consisted of a detailed visual inspection of the structures and the performance of a set of tests and measurements. A statistical analysis of the frequency and variety of the pathologies found is presented, as well as a comparative study of the evolution of the carbonation process within the structural elements and the influence of the coating on the carbonated depth.

Deck parkings' structural type

\section{DESCRIPTION OF THE DECK PARKINGS INSPECTED}

The deck parkings inspected were part of the following commercial enterprises, built in the years given below.

- Modelo Hypermarket of Santarém, 1995 (DP1);

- Modelo Hypermarket of Portimão, 1990 (DP2);

- Modelo Hypermarket of Albufeira, 1989 (DP3);

- Modelo Hypermarket of S. João da Madeira, 1994 (DP4);

- Continente Hypermarket of Vila Nova de Gaia, 1989 (DP5);

- Continente Hypermarket of Viana do Castelo, 1993 (DP6);

- Sonae Building in Matosinhos, 1993 (DP7);

- Continente Hypermarket of Matosinhos, 1993 (DP8);

- Modelo Hypermarket of Vale de Cambra, 1996 (DP9);

- Modelo Hypermarket of Ovar, 1995 (DP10);

- Continente Hypermarket of Amadora, 1994 (DP11);

- Continente Hypermarket of Seixal, 1994 (DP12);

- Modelo Hypermarket of Amarante, 1996 (DP13). 
The structural types of the deck parkings inspected, which were all in reinforced and/or prestressed concrete, may be grouped in the following way.

- DP1, DP9, DP10, DP11 and DP13 were made of hollow slabs, supported by beams (both elements were prefabricated) and the latter by column corbels (top of Figure 1); the beams were connected to the columns with concrete cast in situ in the cases of DP1, DP9, DP10 and DP13.

- DP2, DP3 and DP5 were made of waffle slabs with recoverable moulds, directly supported by columns.

- DP4, DP6, DP7, DP8 and DP12 were made of П-shaped prefabricated elements (bottom of Figure 1), standing side by side, supported by
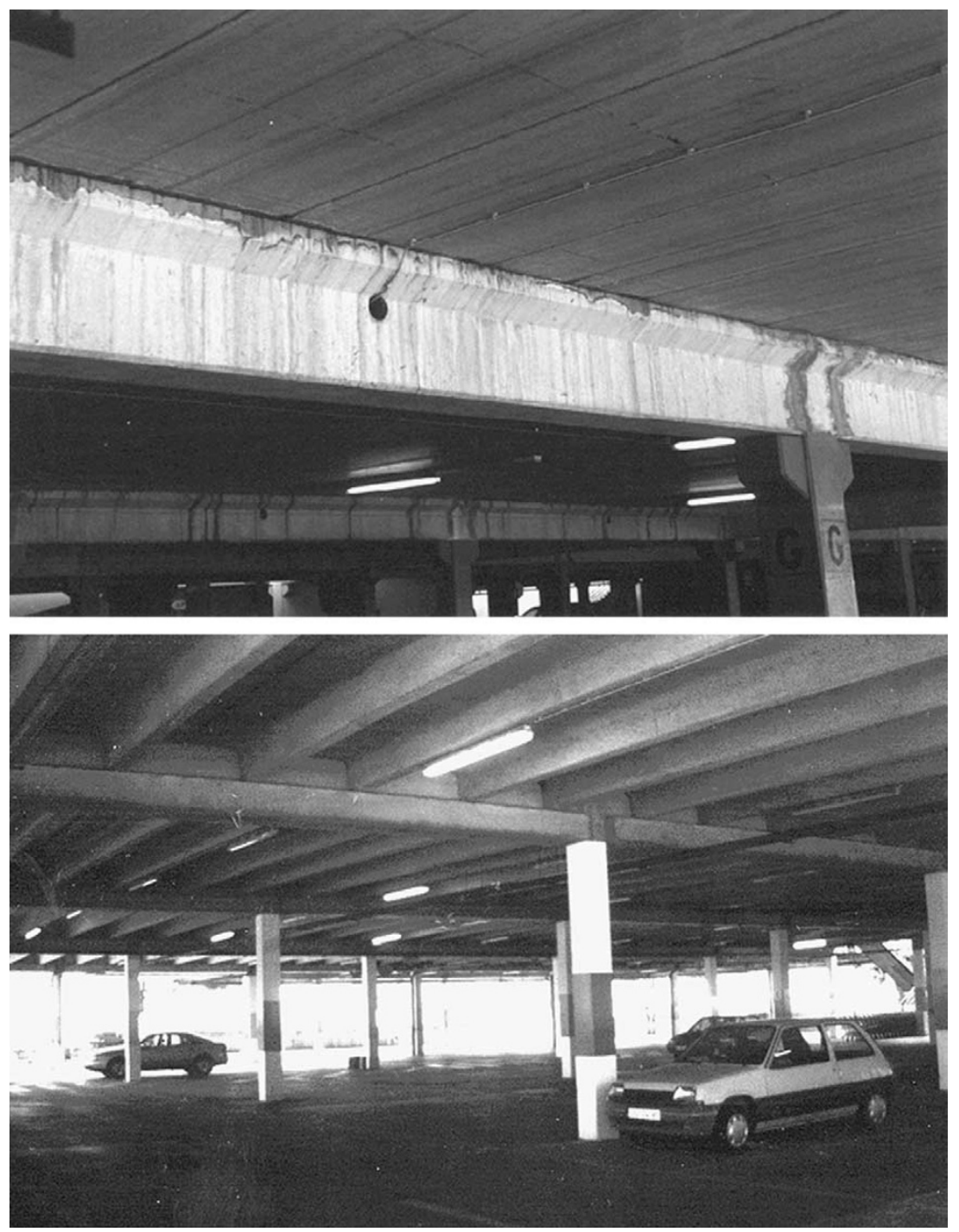

Figure 1: Hollow slabs supported by beams (top) and П-shaped prefabricated elements (bottom) 


\section{Defects frequency}

\section{Water-related structural defects}

beams with an inverted T-shape and connected to the columns with concrete cast in situ and metallic ties (all these elements were prefabricated).

\section{RESULTS OF THE VISUAL INSPECTION}

\section{General remarks}

The inspection campaign for the deck parkings was carried out in order to detect anomalies of two main types: those associated with problems of mechanical behaviour and those resulting from the degradation of the materials with time. The pathologies found were then divided into three groups: structural or construction pathologies, durability pathologies and non-structural pathologies. Next, an analysis of the frequency and variety of the pathologies found was presented for each group.

\section{Structural or construction pathologies}

During the inspection of the deck parkings, various structural anomalies were detected which were problematic from an aesthetic and functional point of view and hinted at structural safety problems. Table 1 presents the statistical survey data for the frequency and variety of these pathologies.

By analysing Table 1 it can be concluded that the most frequent structural anomalies are infiltration of various origins (8) and the existence of wide-open expansion joints (7). These anomalies are somehow related since the greatest part of the infiltration occurred through the non-filled expansion joints. The infiltration problem shows up in the structures cast in situ (top of Figure 2) and in the prefabricated ones (bottom of Figure 2). Such infiltration is associated with deficient drainage and waterproofing of the pavement and even, in some cases, with the non-existence of the latter. The solution to these problems depends on the re-levelling of the pavement, thus guaranteeing proper drainage, waterproofing of the pavement and remaking the expansion joints with a tight material (such as a rubber stripe under compression).

Table I: Structural pathologies detected in the inspection of the deck parkings

\begin{tabular}{lc}
\hline Description & Frequency (\%) \\
\hline I. Cracking and spalling of the columns & 62 \\
2. Cracking of the brick masonry walls & 62 \\
3. Cracking of the corbels & 8 \\
4. Cracking of the slabs and/or beams & 77 \\
5. Cracking of the beams' supports & 69 \\
6. Cracking of the retaining walls & 31 \\
7. Open expansion joints & 85 \\
8. Infiltration of various origins & 92 \\
9. Porous concrete & 23 \\
10. Lack of verticality of structural elements & 15 \\
I. Structural element damaged by vehicle impact & 15 \\
I2. Structural element near collapse & 8 \\
13. Deterioration resulting from previous defective repairs & 8 \\
14. Holes drilled in slabs cutting reinforcement bars & 8 \\
\hline
\end{tabular}



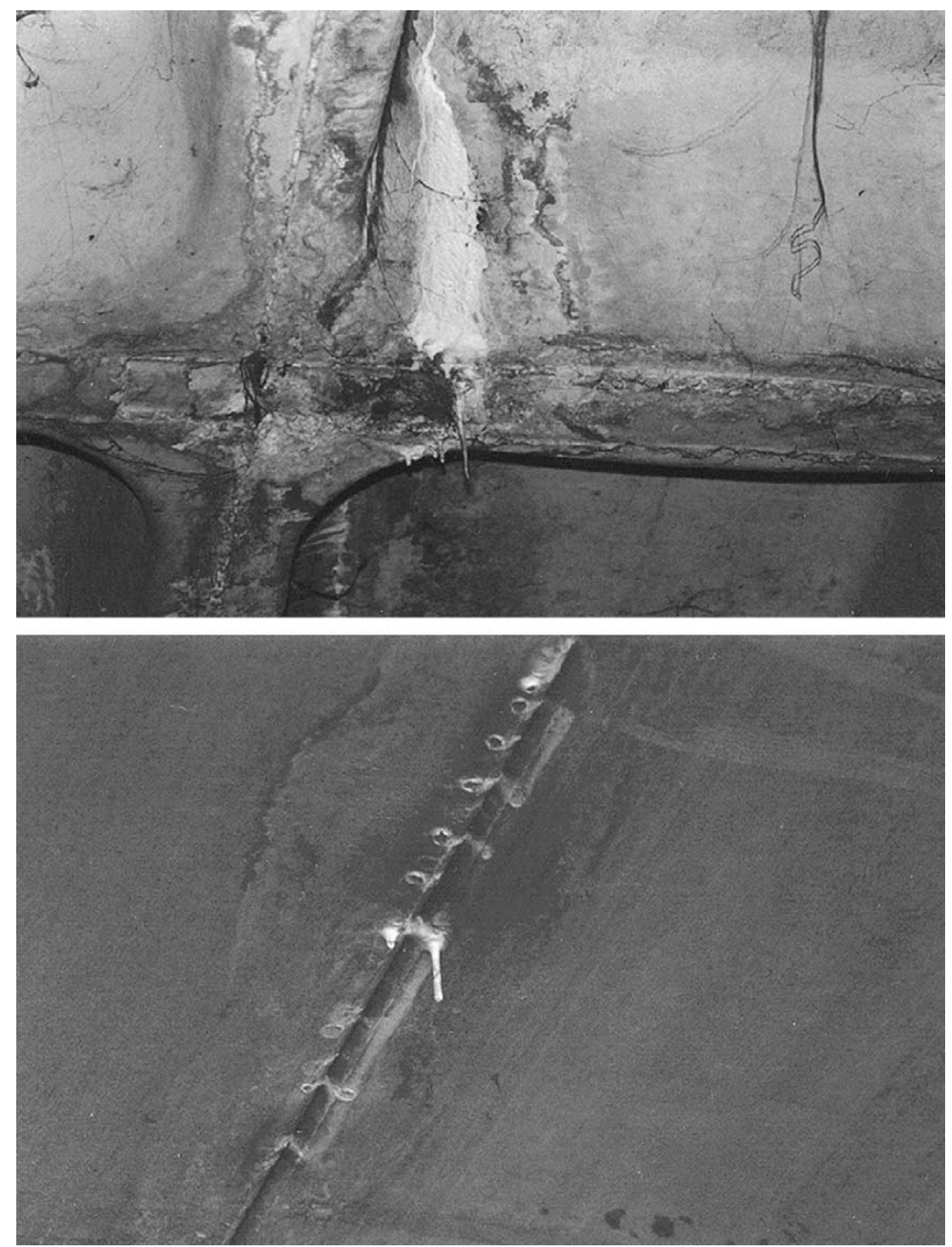

Figure 2: Infiltration in a waffle slab (top) and in a prefabricated panel (bottom)

\section{Cracking}

In addition, by analysing Table 1 it can be concluded that the pathologies related to cracking of structural elements $(1,3-6)$ or brick masonry walls (2) are very frequent. Cracking of the columns (1) shows up more frequently in prefabricated elements and is generally associated with thermo-hygrometric movements of the structure, resulting from temperature variations but essentially from shrinkage of the concrete slab. Indeed, cracking is more pronounced near the façades (top of Figure 3) and it decreases gradually towards the inner part of the deck parkings. Cracking of the slabs and beams (4) is also intimately related to the dribbling of rainwater and consequently the occurrence of stalactites. In slabs, both those cast in situ and prefabricated ones, bending and shrinkage cracks were detected, the first due to either a deficient design calculation or excessive live loads. 

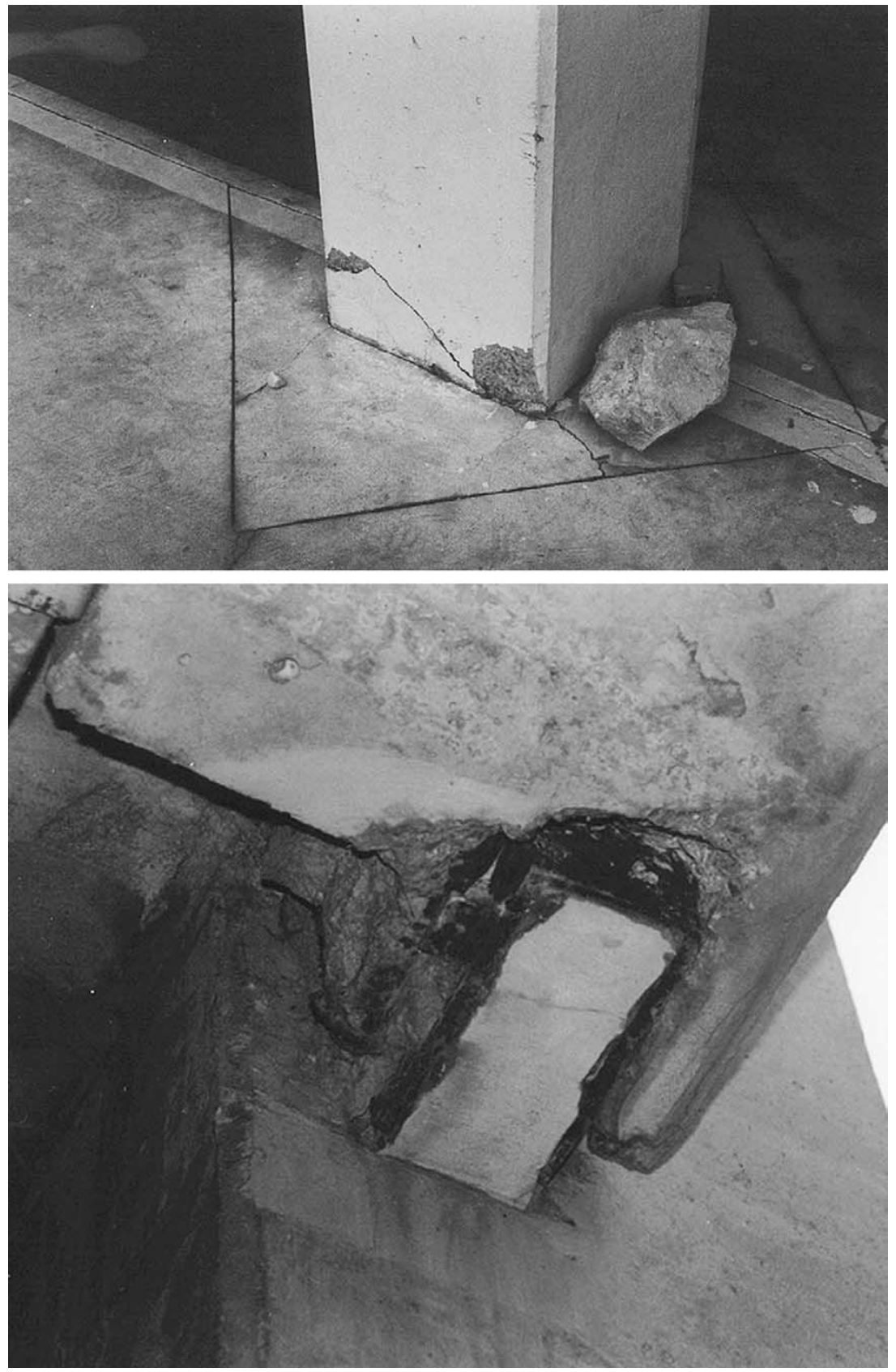

Figure 3: Cracking of a façade column (top) and a beam support (bottom)

Cracking of the beam supports (5) shows up frequently in deck parkings designed with П-shaped prefabricated elements. In these cases, the beams-to-columns connecting system was accomplished with metallic supports, subsequently covered with mortar. Due to the structure's movements, this mortar was cracked in almost all of the supports, and had even fallen down from some of them exposing the metallic elements (bottom of Figure 3). 
Cracks observed in brick masonry walls (2) resulted mostly from thermo-hygrometric movements of the structure or from slight foundation settlements. They were detected only in buildings made of prefabricated elements.

An excessive porosity of the concrete (9) was detected only in the deck parkings with a structure made of elements cast in situ. This pathology resulted mostly from deficiencies in the construction process. In some cases, areas with deficient concrete and exposed reinforcement were visible (top of Figure 4).

Pathologies such as structural elements with a lack of verticality (10) and vehicle impact symptoms (11) (bottom of Figure 4) were less frequent, and it is significant that the former was detected only in elements cast in situ. The impact of vehicles on slabs and beams resulted from a
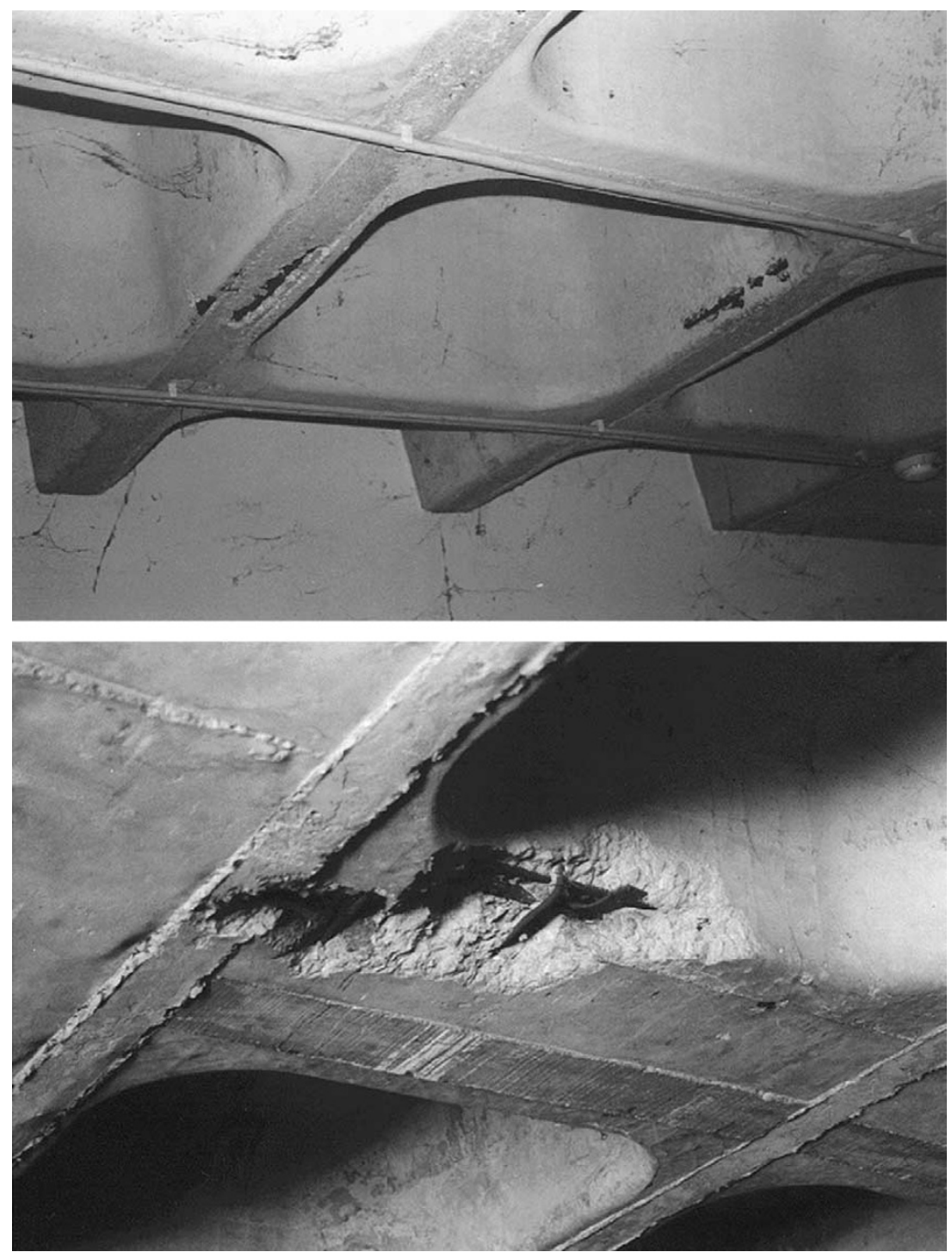

Figure 4: Area with deficient concrete (top) and deterioration caused by the impact of vehicles (bottom) 
deficient controlling system of protection of the vertical clearance inside the deck parkings (and some users' carelessness) and caused spalling and various other types of deterioration in these structural elements.

\section{Water-related durability defects}

\section{Durability pathologies}

During the visual inspection of the deck parkings, several durability pathologies were found related mostly to reinforcement oxidisation and the transportation of salts within the concrete. The statistical survey data for the frequency and variety of these pathologies are presented in Table 2 .

As shown in Table 2, the presence of water dribbling with signs of rust and salts (1) was detected in all the deck parkings inspected. This condition indicates the onset of durability problems resulting from reinforcement oxidisation and the transportation of concrete salts (top of Figure 5). This rusting of the reinforcement was visible in the brownish colour of the dribbling situations and the transportation of concrete salts was embodied by the presence of stalactites and whitish stains near the dribbling.

Also by analysing Table 2 it can be concluded that the detection of exposed reinforcement bars already in the process of corroding (2) was not very frequent. This pathology occurred mostly in the buildings made with elements cast in situ (bottom of Figure 5), and represented only 23 per cent of the deck parkings inspected. As a matter of fact, the better quality of the concrete and the guarantee of designed reinforcement bars covering the prefabricated elements make their use considerably preferable to elements cast in situ. Among the deck parkings designed with prefabricated elements, signs of reinforcement corrosion were detected in only two cases (20 per cent) and those were near the staircases (a very exposed area).

In some deck parkings, deterioration of the slab in areas where holes had been drilled (3) was detected (top of Figure 6). Many cases of water dribbling were also noticed near the areas mentioned. In only one of the buildings inspected was the presence of condensation and signs of fungus growth resulting from a high humidity content (4) registered. Such a situation can occur in areas of the slab situated under shopping mall refrigeration units, where surface temperatures in the concrete are much lower than average. Also in only one of the deck parkings inspected were dark areas detected where symptoms of having undergone a small fire, possibly in a vehicle, were apparent (bottom of Figure 6).

Table 2: Durability-related pathologies detected in the inspection of the deck parkings

\begin{tabular}{lc}
\hline Description & Frequency (\%) \\
\hline I. Water dribbling with signs of rust and salts & 100 \\
2. Reinforcement corrosion & 38 \\
3. Slab deterioration near faulty pipes & 23 \\
4. Condensation/funguses & 8 \\
5. Fire symptoms & 8 \\
\hline
\end{tabular}



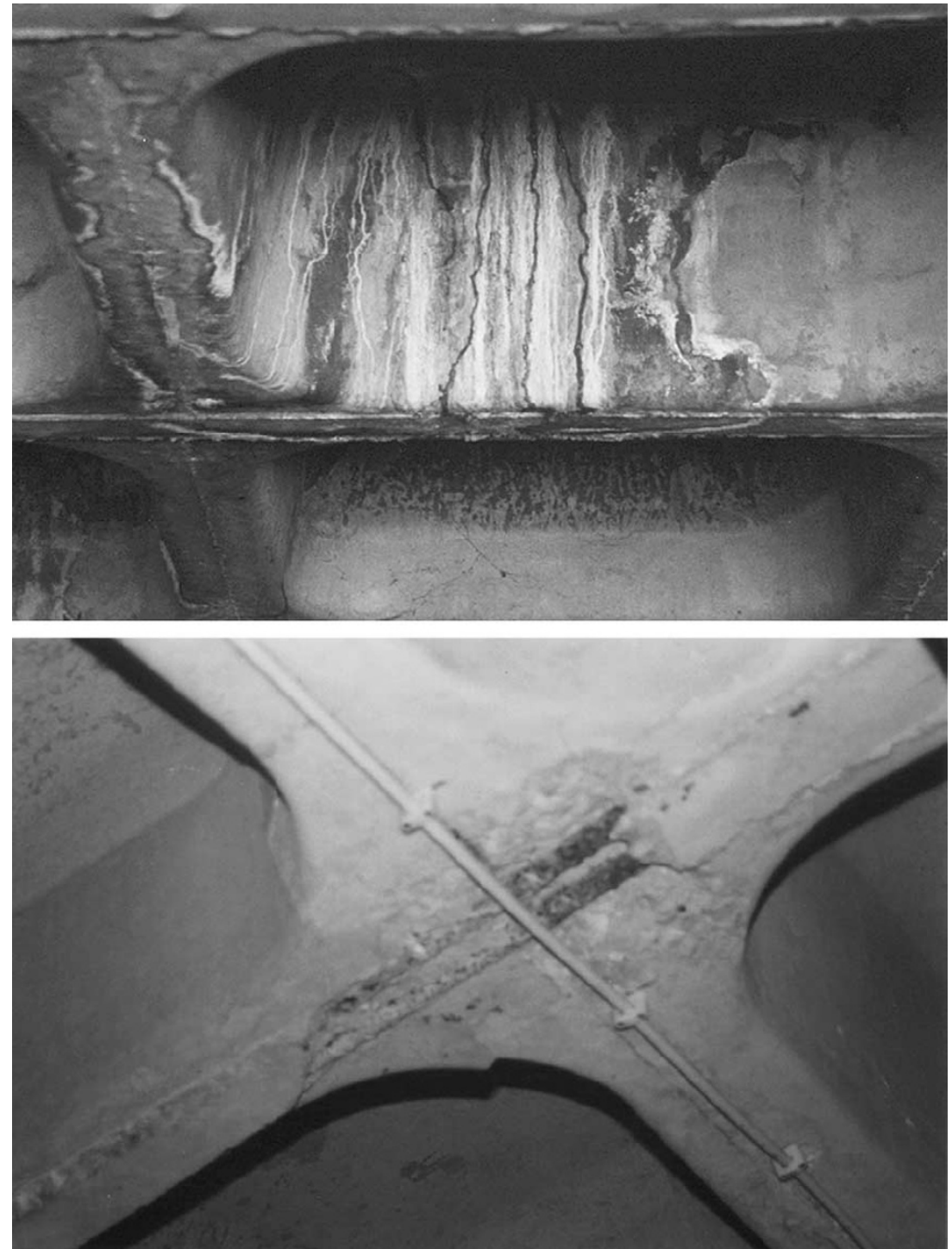

Figure 5: Water dribbling in a slab with rust stains (top) and corroded reinforcement from a slab (bottom)

The drainage problem

\section{Non-structural pathologies}

During the visual inspection of the deck parkings, some non-structural pathologies were registered such as deficiencies in the drainage and lighting systems, pavement cracking, deterioration of the railings etc. In Table 3 the frequency and variety of the main pathologies of this type are presented.

An analysis of Table 3 leads to the conclusion that there were deficiencies in the drainage system (1) in all the deck parkings inspected. These deficiencies were associated with insufficient slopes of the drains, leading to water stagnation, clogging or deterioration of the gullies and the presence of damaged drainage pipes (top of Figure 7), or even in some cases their non-existence. It must be pointed out that this pathology is 

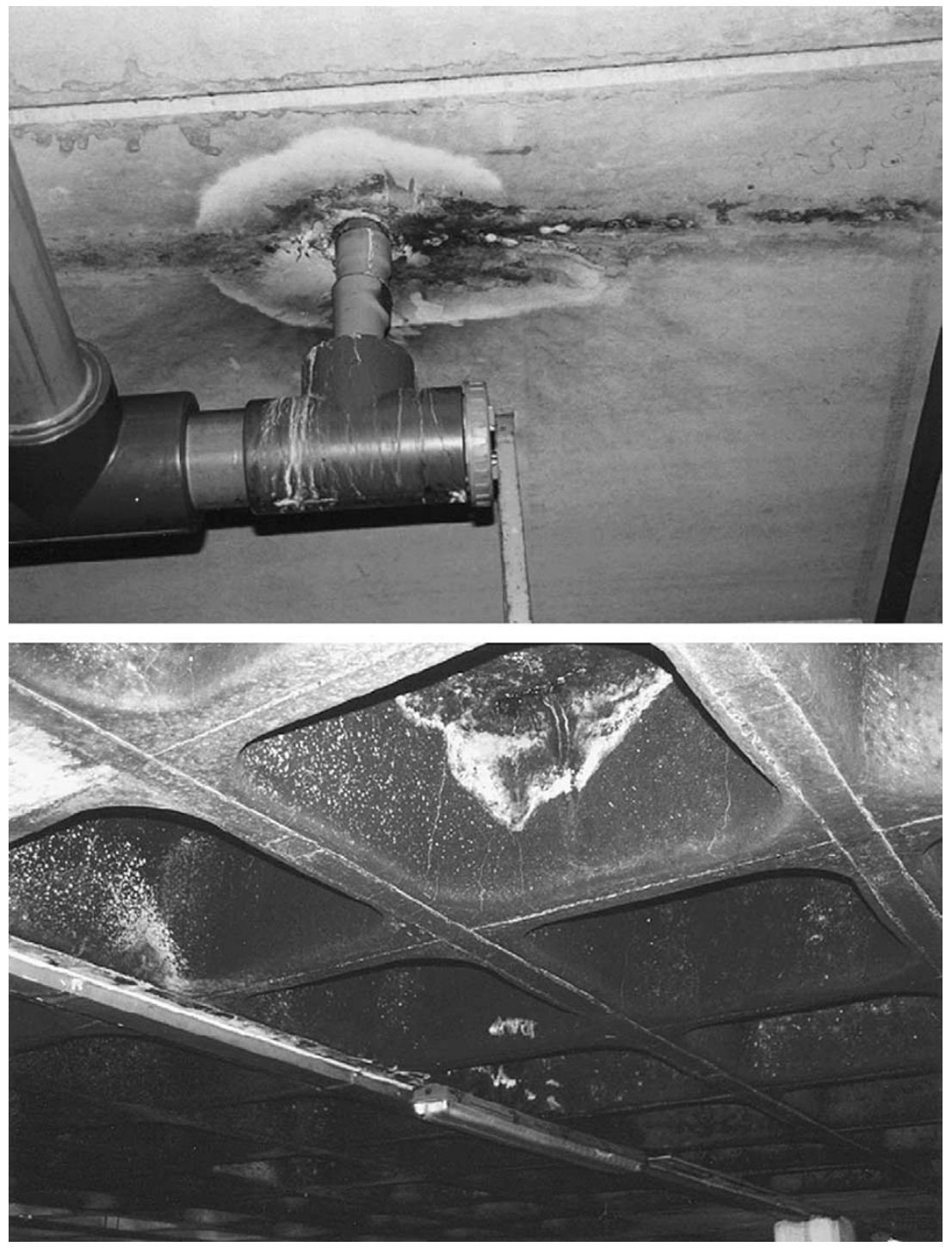

Figure 6: Deterioration near faulty piping (top) and areas with symptoms of a fire (bottom)

directly related to structural or construction pathologies, such as rainwater dribbling, excessive gaping of expansion joints and cracking of slabs and/or beams, as well as durability pathologies, such as water dribbling with signs of oxidisation and salts and reinforcement corrosion.

Table 3: Frequency and variety of the main non-structural pathologies

\begin{tabular}{lc}
\hline Description & Frequency (\%) \\
\hline I. Drainage system deficiencies & 100 \\
2. Lighting system deficiencies & 92 \\
3. Railings' deterioration & 54 \\
4. Pavement cracking & 23 \\
5. Deterioration of curbs and sidewalks & 8 \\
\hline
\end{tabular}




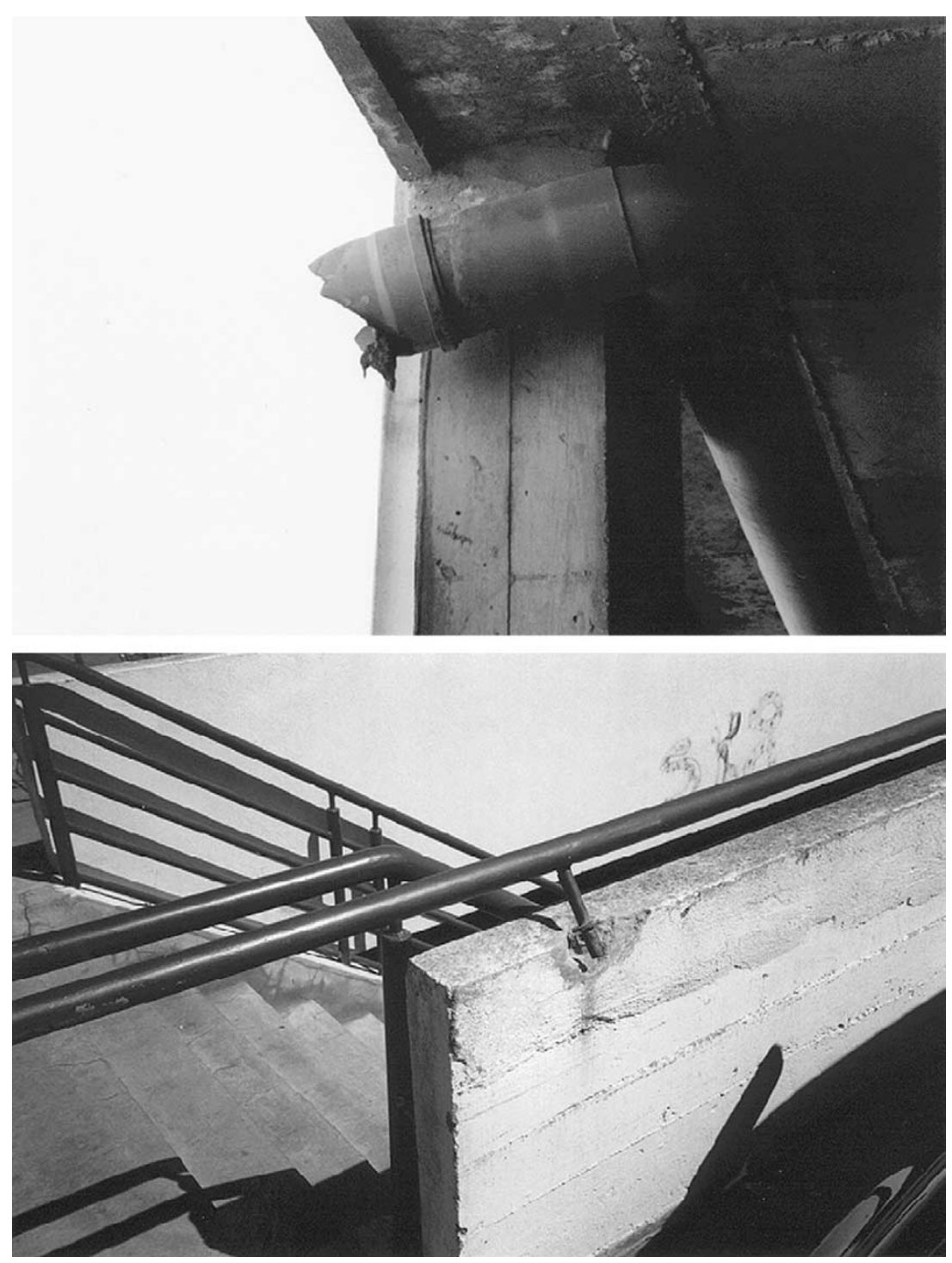

Figure 7: Damaged drainage pipe (top) and spalling of the concrete near a railing fastening (bottom)

\section{The lighting system}

\section{Other non-structural defects}

In addition, from an analysis of Table 3 it can be concluded that pathologies associated with deficiencies of the lighting system (2) show up very frequently, such as damaged metallic encasings and fused light bulbs, in many cases situated almost directly under expansion joints with infiltration problems, probably leading to an electrical short-circuit.

The deterioration of the railings or their fastening areas to the pavement structure (3) was registered in about half of the deck parkings inspected. In the latter areas, in some cases spalling of the concrete (bottom of Figure 7) was detected, caused by the ties themselves and the structure's movements.

Some of the less frequent pathology occurrences included cracking of the pavement floor (4), especially those situated higher up, and deterioration of the curbs and sidewalks (5). On the floors under cover, 
cracking was superficial, probably due to shrinkage, while on the exposed floors the cracks were wider. It must be pointed out that this pathology (4) was registered only in the deck parkings designed with concrete cast in situ.

\section{CARBONATION MEASUREMENTS}

\section{Description of the test}

\section{Phenolphthalein testing}

The carbonation front depth was determined by using a spray of phenolphthalein solution, which changes colour (from dark rose to colourless) and thus indicates the concrete areas with a $\mathrm{pH}$ below 9, which determines the region where the natural alkalinity of the concrete has been neutralised. This situation, when combined with oxygen and humidity in large enough quantities, may lead to the initiation of reinforcement corrosion.

Measurements were performed at the deck parkings in holes made with a $25 \mathrm{~mm}$-diameter drill. The length of the holes increased gradually from the surface in order to identify better the interface between the carbonated region and the non-carbonated region, ie the carbonation front. The depth of carbonation was measured with a calliper rule with a device at its end to facilitate the visualisation of the reference position of the concrete surface. In the case of the columns, tests were performed both in elements covered with paint and in elements with exposed concrete. The main objective of this comparison was to demonstrate the positive influence on the structural elements of the use of paint in the evolution of the carbonation front over time.

\section{Carbonation depth results}

\section{The effect of compression strength}

\section{Linear correlations}

\section{Results analysis}

During these tests, the values of the carbonation front depth were registered both in linear structural elements (columns and beams) and in plane elements (slabs and retaining walls). Since the ages of the deck parkings inspected varied, for each value registered a proportionality coefficient between the carbonation depth (d) and the square root of time $(\mathrm{t})$ - from here on called the carbonation coefficient $(d=C \sqrt{\mathrm{t}})$ was determined. Figures 8 and 9 , concerning prefabricated elements and elements cast in situ respectively, graphically represent the variation of the carbonation coefficient with the average compression strength of the concrete $\left(\mathrm{f}_{\mathrm{cm}}\right)$, evaluated by using a sclerometer.

The first conclusion that can be drawn from Figures 8 and 9 is the extremely high scatter of the results, expressed in the low values of $\mathrm{R}^{2}$ in all the linear regressions. This situation can be explained by various factors: the variability of the results normally associated with the use of the sclerometer, a test more appropriate for comparative analyses of different concrete areas than for the determination of the absolute value of their respective compression strengths; the fact that the phenolphthalein test in situ is subject to various small imprecisions, more so because the depth of the carbonation front varied according to local effects such as the existence of coarse aggregates; the fact that all the structures inspected 


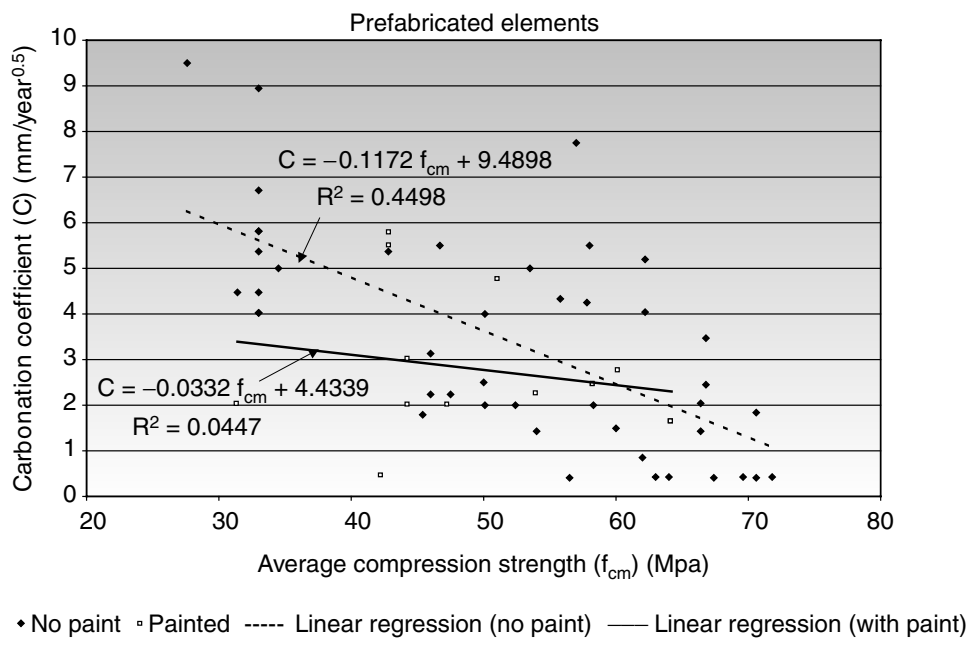

Figure 8: Carbonation coefficient $(C)$ versus concrete average compression strength $\left(f_{\mathrm{cm}}\right)$ for prefabricated elements

were very young (the majority were less than five years old) increased the relative importance of the factors referred to above; and the variability of natural phenomena, which are generally more complex than the theoretical models aimed at predicting them. Nonetheless, it seems obvious from these results that the compression strength of the concrete, just by itself, is not enough to make a solid prediction of the rate of penetration of the carbonation front, ie other factors need to be taken into account such as the quality of the workmanship during concrete casting and compaction and the naturally aggressive environment.

Based on the diagrams presented in Figures 8 and 9, it can be concluded that, both for the deck parkings designed with prefabricated elements and those with elements cast in situ, the values of the carbonation coefficient (C) decrease as the average compression strength

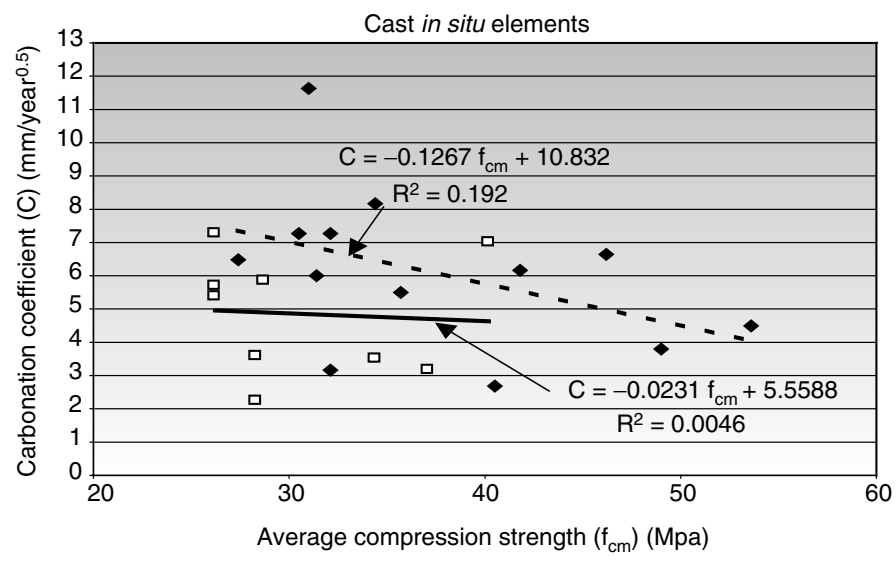

- No paint $\square$ Painted ----- Linear regression (no paint) — Linear regression (with paint)

Figure 9: Carbonation coefficient $(C)$ versus concrete average compression strength $\left(f_{\mathrm{cm}}\right)$ for elements cast in situ 
The effect of painting increases. For the elements that had been painted, this conclusion is not as pronounced or obvious due to the small variations in the compression resistance of those elements, since in these deck parkings only the columns had been painted.

Again through an analysis of Figures 8 and 9, the favourable effect of painting the elements can be confirmed, meaning that for equal compression strength values the carbonation coefficient was greater for the elements that had not been painted. This effect becomes more pronounced as the compression strength of the concrete lessens, or, indirectly, as the permeability of the mortar matrix increases. Once a certain level of compression strength was attained, the type of paint used (water-based paint is relatively permeable and not designed especially for the purpose of protecting concrete from the entry of aggressive elements from the outer environment) ceased to have any effect on the carbonation progress, meaning that the permeability of the paint was at least equal to the permeability of the mortar matrix.

In both Figures 8 and 9 the linear regression representations of the variations in the carbonation coefficient with the average compression strength are presented (for elements without paint and those that have been painted), where this variation is significant only for the non-painted elements. Based on the diagrams, it can be concluded for these elements that the carbonation coefficient is more sensitive to a variation in the average compression strength of the deck parkings cast in situ than for those with prefabricated elements.

\section{CONCLUSIONS}

This paper presents the main pathologies detected during an inspection campaign performed on 13 deck parkings in various regions of Portugal. It also presents relationships between the depth of the carbonation front and the average concrete compression strength (as estimated with a sclerometer), registered both in buildings designed with prefabricated elements and those built with elements cast in situ. Various main conclusions can be drawn from these inspections and they have been organised into three groups below.

In terms of the pathologies found:

- the pathologies can be grouped as structural, durability-related and non-structural and they were interrelated;

- the most frequent structural pathologies were cracking in various elements and water-related problems;

- in terms of durability, reinforcement corrosion and water-related problems were the most frequent;

- again, for non-structural pathologies, water was the main problem and the systems with most anomalies were drainage and lighting;

- these structures, being exposed to the aggressiveness of the environment, were subject to extremely fast degradation mechanisms and exhibited important problems even within five years of construction. 
In terms of service life prediction:

Service life prediction

\section{Design rules for deck parkings}

- predicting the initiation period of corrosion of the reinforcement within concrete, when associated with the carbonation process, is a complex matter that must not be over-simplified;

- correlations between the depth of the carbonation front and concrete compression strength were insufficient for this purpose since they exhibited very high scatter; nevertheless, it was found that the carbonation process tends to slow down as the concrete strength increases;

- in order to obtain better correlations, other factors besides concrete strength must be taken into account;

- the coating of concrete elements and the quality of their casting and compaction (prefabrication versus casting in situ) significantly influenced these correlations.

In terms of design rules for deck parkings:

- the upper floor of deck parkings is subject to extremely rough environmental conditions;

- since water penetration is the starting point of the majority of the potential problems, the upper floor must always be waterproofed, the expansion joints must be adequately designed and maintained and the drainage system must be impeccable (in terms of slopes, drain capacity, positioning and materials, preventing water from flowing over concrete surfaces and maintenance);

- as the quality control of prefabricated concrete elements is usually much more effective than that of concrete cast in situ and, furthermore, the concrete strength is much greater (therefore, permeability would be expected to be much lower), this must be taken into account in the initial design phase;

- standard paints provide some protection to exposed elements but only when the concrete is significantly permeable (either deficiently cast in situ and/or with very low compression strength); in order to obtain really effective protection, properly designed outer protections are needed.

\section{Acknowledgments}

This contribution has been prepared based on a number of reports developed within ICIST/IST by the authors, at the request of the owner of the deck parkings, Sonae, and the firm responsible for their use and maintenance, IGI. 